\title{
Factors That Affect Staff Morale in Tertiary Hospitals in Malawi: A Case Study of Kamuzu Central Hospital
}

\author{
John Benson Chipeta \\ HIV/AIDS Section, UNICEF, Lilongwe, Malawi \\ Email: jbchipeta@gmail.com
}

Received 6 October 2014; revised 2 November 2014; accepted 1 December 2014

Academic Editor: Luca Solari, University of Milan, Italy

Copyright (C) 2014 by author and Scientific Research Publishing Inc.

This work is licensed under the Creative Commons Attribution International License (CC BY).

http://creativecommons.org/licenses/by/4.0/

(c) (i)

\section{Abstract}

Staff morale is low among medical and nursing staff in Malawi's health facilities. This leads to voluntary attrition or unfavorable survival strategies among members of staff. This study sought to determine critical factors that affected staff morale at Kamuzu Central Hospital (KCH). This was a case study research design. Quantitative data were collected through structured questionnaires filled in by doctors, registered nurses and clinical officers. Qualitative data were collected through focus group discussions with the same cadres. An in-depth interview was done with one human resource officer. Key factors that affected staff morale at $\mathrm{KCH}$ were: inadequate resources for work, poor compensation, heavy workload, inadequate performance management, lack of career development and lack of training opportunities. Nurses further complained of inadequate management support. Thirty-one percent of the respondents were very dissatisfied with their jobs and $57 \%$ were intending to leave within 12 months. Job satisfaction was associated with management responsiveness ( $\mathrm{p}$-value 0.009 ).

\section{Keywords}

Human Resource Management, Staff Morale, Medical and Nursing Staff

\section{Background and Introduction}

Malawi is a densely populated country with a population of 14.5 million and a high population growth rate of 2.3\% (Ministry of Economic Planning and Development, 2011) [1]. The country’s dependence on agriculture renders its economy vulnerable to shocks. The country faces a number of socio-economic challenges including 
inadequate skilled human resources (HR). The Malawi Growth and Development Strategy (MGDS) is the medium term national development strategy formulated to attain the country's long term development aspirations. The MGDS outlines key priority areas which are central to the achievement of sustainable economic growth and wealth creation in Malawi. Four of these are entirely within the health sector (Ministry of Health-HSSP, 2011) [2]. The MGDS is implemented through various sector-wide strategic plans. Sector specific strategic plans feed into the MGDS. The 2011-2016 Malawi Health Sector Strategic Plan (HSSP) feeds into the MGDS as regards health sector strategic issues. Goals of the HSSP are aligned to health related thematic areas of the MGDS. One of the urgent challenges to successful implementation of the HSSP is the inadequate capacity of HR for health.

HR for health is a challenge in Sub-Saharan Africa. Medical and nursing staff to population ratio in Africa has all the time lagged behind the rest of the world. On average, African countries have about 20 times fewer doctors and 10 times fewer nurses than developed countries [3]. Malawi, like many Sub-Saharan African (SSA) countries, is facing a HR for health crisis. Inadequate investment in the health sector and a weak policy environment resulted into a significant decline in the supply of professional health workers in Malawi in the late 1990s [4]. By 1999, the health sector openly acknowledged a health worker crisis in the country. The reasons underlying the crisis were multiple and included limited output from medical and nursing training institutions and high attrition rates. Furthermore, during the same period registered nurses and doctors emigrated to Europe and other rich countries [4]. Much of the investment made in training health personnel by the government of Malawi is being lost as increasing numbers of professional and technical members of staff choose to move out of the public sector [5].

The Ministry of Health $(\mathrm{MoH})$ in Malawi has a complex administrative arrangement in the public sector which leads to ineffective and insufficient use of staff [6]. Most of the HRM and HR planning is done at national level leaving health facilities with little or no autonomy to implement changes needed within their systems. Despite various efforts towards curbing the HR crisis, challenges continue to exist in Malawi. Staff morale is low among staff working at all levels of the health systems in Malawi [4]. Staff morale has a direct impact on staff retention and performance. This study focused on issues of staff morale and its implications.

Health workers are constantly resigning from hospitals as a result of various demoralizing factors. On the other hand, low morale amongst existing health workers leads to low quality patient management which may lead to poor treatment outcomes. Existing staff in tertiary hospitals employ a range of survival strategies including private business and dual practice which negatively impact on the quality of health care service delivery. Understanding factors that demoralize professional staff in tertiary referral hospitals is a prerequisite to formulation of effective HRM policies and strategies that can motivate and retain them. Referral hospitals handle patients in critical conditions. As such, it is imperative to seriously take care of staff welfare and development needs in these hospitals. This study sought to determine critical factors that affected staff morale at KCH; and in so doing, recommend strategies to improve staff motivation, retention and performance. Specifically, the study aimed at investigating effects of the work environment, HR policies and HR strategies on staff morale.

\section{Literature Review}

\subsection{Impact of Work Environment on Staff Morale}

Several reasons have been attributed to the health workforce crisis in Sub-Sahara Africa (SSA). These include poor work environment [6]; a work environment comprises the physical geographical location, physical surroundings, conditions of service, management style, chemical and biological environment among other things US Ministry of Health [7]. According to Armstrong [8], management needs to implement steps to create a work environment where employees are self-motivated to perform tasks that exceed management's standards. A healthy work environment does not only benefit employees but also benefits clients, stakeholders and communities. In order to create a good working environment, an institution must ensure safety of staff, provide challenging jobs, control workloads, accommodate views of staff members, trust and respect staff, provide adequate resources, recognize staff contributions and provision of training and development among others [7].

The working environment for health workers in Africa is poor [9]. Critical working environmental factors that can affect staff morale in hospitals include inadequate supervision and support, lack of essential drugs, supplies and equipment, limited career development opportunities, workloads, compensation, inequitable access to training and inadequate housing [5]. Poor working conditions coupled with HIV and AIDS related illnesses among health workers lead to low staff morale, consequently this negatively impacts on productivity and retention of 
staff [4].

Most commonly cited factors leading to the poor working environment in Malawi include poor compensation, lack of continuing education and training opportunities, lack of social and retirement benefits, lack of proper equipment, and poor HR management [6]. Poor working environment is a significant push factor for HR in Malawi [6]. Voluntary attrition of health workers in Malawi relate to the following three aspects: loss to the entire health sector, loss to another employer within the sector; and loss from one posting to another within an organisation; especially from rural to urban areas [10]. Migration of health workers out of the public sector to the private sector or outside Malawi poses major challenges as regards provision of health care services in Malawi. Health professionals that are working at district level in Malawi face a lot of challenges as a result of the poor working environment, more especially when it comes to conditions of services, management support and staff welfare [6].

\subsection{Impact of HR Policies on Staff Morale}

According to Palmer [5], HR policies and management style are central to improving staff morale and retention. Palmer [5] argues that management practices are as important an incentive as pay; providing drugs, gloves, equipment, decent infrastructure and adequate supervision. Current administrative arrangements for public sector management of HR for health are centralised and complex, and impede satisfactory use of staff, despite efforts made by the $\mathrm{MoH}$. For instance, filling of vacant posts and other HR issues are unnecessarily complex and centrally controlled. It is therefore protracted and open to abuse [11]. The slow progress made by MOH to decentralise HR management responsibilities to districts and central hospitals limits the effective management of the most important resource available Ministry of Health [11]. McAuliffe et al. [6] revealed that district hospital managers believe they have no autonomy.

Malawi has a weak career development policy for health workers; career development is one of important means of retaining staff [11]. There is lack of a career structure for some cadres, for instance, clinical officers. This is a serious defect in the HRH system [11]. MoH policies on training and development are unclear at district level [6]. This is a de-motivating factor for both managers and staff. Staff at district level indicated that they are demoralised by lack of career development plans and training opportunities [6]. The latter further revealed lack of rewards for individual performance, poor supervision and lack of performance appraisal at district level.

\subsection{HR Management Strategies and Their Impact on Staff Morale}

A robust HR strategy is a prerequisite to improvement of productivity and effectiveness. Apparently the HR strategy must be aligned with the organization's vision, mission and goals [8]. Creating different strategies for all groups of people in the organization may be necessary, depending on their skills, knowledge and responsibilities [8]. According to Noe et al. [12], HR strategies are developed in such a way that they support organisational business strategies. HR strategies must address business strategic issues such as retaining a vibrant workforce, support organisation growth, outdoing competitors, technological challenges and surviving in the ever changing business environment [12]. Various tactics must be devised and implemented in order to execute strategies [13]. As such, various tactics need to be implemented in order to successfully implement HR strategies.

African countries have employed various HR strategies and tactics to boost staff morale and improve retention. SSA countries are using several tactics to implement HR strategy. These include non-financial incentives; continuing professional development, and opportunities for higher training [14]. Incentives that address social needs were used in several countries, such as: housing in Lesotho and Tanzania; staff transport in Lesotho and Zambia; childcare facilities in Swaziland and free food in Mozambique and Mauritius [15].

In Malawi, the MoH has put in place a range of HR tactics to help boost staff morale. Health workers are paid locum, a particular amount of money to work unscheduled shifts. Other tactics operational at district level are advocating for staff promotion, organizing more in-service training, providing staff with uniforms, providing transport and giving staff time [16]. All members of staff were targeted by the 2005-2011 EHRP interventions that include a 52\% salary top up, housing allowance for some cadres, engagement of international volunteers, technical assistance and engagement of newly trained staff from training institutions [17].

\subsection{Factors That Enhance Staff Morale}

People have various and different reasons for working. Every individual works to obtain something in return. 
What the employee wants has a direct impact on employee morale, employee motivation and the quality of life [8]. According to Armstrong [8] employees seek either intrinsic or extrinsic benefits from an organization. Intrinsic benefits develop from performing the work itself, such as feeling important and learning valuable skills; extrinsic needs include compensation, benefits and welfare. Understanding staff needs and motivation issues deserve attention if an institution is to get returns on resources spent on staff and if an institution is to attract staff [12]. Understanding the main factors that contribute towards job satisfaction levels and diminishing intention to leave is an important strategy towards retention of health care workers [18]. According to Armstrong [8] the Maslow's hierarchy of needs can be helpful in understanding what motivates employees. Maslow identified five levels of needs that must be satisfied for an employee to be motivated. An employee can't move up the hierarchy unless the basic needs have been satisfied.

The Herzberg's motivation-hygiene theory states that there are factors in the workplace that cause job satisfaction, while a different set of factors cause dissatisfaction. This theory suggests that to improve job attitudes and productivity, HR managers must recognize and manage both sets of characteristics without assuming that an increase in satisfaction leads to a decrease in dissatisfying factors [19]. On the other hand, Grobler et al. [20] cites the theory of McGregor, which indicates that organizations can manage employees in two ways, theory $\mathrm{X}$ or $\mathrm{Y}$, as another way of making choices towards staff motivation. McGregor's theory X assumes that employees are lazy hence require hard HR practices to ensure that they perform while theory $\mathrm{Y}$ is more of a positive and participative approach. To motivate employees, theory $\mathrm{Y}$ is the model assumed to improve employee productivity.

Noe et al. [12] notes that employees compare their pay levels with those they perceive prevail in other organizations. Such comparisons have an influence on employee attitude and retention. Armstrong [8] suggests that compensation alone cannot result in staff retention. Furthermore, a survey conducted by Deloitte and Touch, on retention of staff in USA ranked compensation fifth as one of ways for retaining staff; top measures included increased flexible work schedules and career path opportunities [21]. However, economic downturn makes compensation budgets very strained. This makes it difficult to satisfactorily motivate and retain employees [4]. Armstrong [8] argues that in order to motivate and retain staff, organizations need to implement a market driven human resource management (HRM) strategy, which naturally factors in attractive terms and conditions of service.

A study conducted by a multi-agency project The Health Systems Strengthening for Equity Project (HSSE) in three African countries, revealed that between one-quarter and one-third of staff surveyed had seriously thought about leaving their current positions [22]. A significant portion of motivation levels could be explained by staff perceptions of adequate supervision, support from management, adequate pay for work done, and opportunities for career advancement [22]-[24]. A study conducted by Mangham [18] revealed that Malawian registered nurses feel that salary increases would be a principal factor to improve their motivation and hence boost their morale; however it has to be supplemented with improved resource availability and access to further education. Poor health facility management, was cited as one of key factors that affect staff morale. Although the study concluded that pay was the most important attribute, Manghan [18] calls for further research to establish the relationship between an increase in the level of pay and an improvement in the retention of registered nurses in the public sector.

Since compensation is reported to be a major factor in the decision to migrate, some SSA countries have introduced salary top up allowances and other kinds of benefits and allowances for some cadres of health workers [25]. However, monetary incentives alone cannot alter the migration of health workers. Being responsive to concerns of health workers regarding their general working conditions and directing resources at improving the working environment within which they work may be more effective. A study by World Health Organization (WHO) revealed that Ugandan health workers showed low levels of intention to migrate despite relatively low pay incentives [26]. The WHO study found non-monetary incentives to be effective in motivating health workers [26].

\section{Methodology}

\subsection{Research Design}

The research strategy employed was an "embedded case study" according to Saunders et al., [27]. KCH was the case with 3 main sub-units, that is, doctors, clinical officers and nurses. The case study strategy was chosen because KCH is a typical case of a public tertiary hospital in Malawi. Findings from this study gave an indication on 
the status in other tertiary hospitals in Malawi.

\subsection{Study Site and Population}

The study site was Kamuzu Central Hospital located in Lilongwe, the capital city of Malawi. The study population was medical staff consisting of doctors and clinical officers; and registered nurses. These cadres were selected because they are the most senior skilled cadres that provide complex and lifesaving medical and nursing services at $\mathrm{KCH}$. Most importantly, voluntary attrition seemed to be highest among these cadres both at $\mathrm{KCH}$ and at national level.

\subsection{Sampling Design}

Convenience sampling was employed for KCH HR managers. Medical and nursing members of staff were randomly selected. Single stage stratified random sampling of doctors, clinical officers and nurses were done. Each cadre of staff was regarded as a stratum. Respondents were randomly selected from lists of doctors, nurses and clinical officers collected from the HR manager those who were busy or did not accept to be interviewed were skipped. A probability proportional to size approach was used, [28]. The fraction of members of staff drawn from each stratum was proportional to the size of the stratum. Sampling frames for the three strata were as follows; 71 registered nurses, 61 doctors and 46 clinical officers.

Morris [28] argues that when the target population is less than 5000, or if the sample size is a significant proportion of the population size, then the standard sampling and statistical analysis techniques need to be changed. Morris [28] recommends selecting the entire population to achieve accuracy for small populations like those of employee cadres at $\mathrm{KCH}$. However given the fact that the researcher had budgetary constraints and that medical personnel are extremely busy, a total of 60 people were randomly selected and given questionnaires. The study sample included 20 doctors, 25 nurses and 15 clinical officers. Due to time constraints among staff questionnaires were filled by 50 respondents.

\subsection{Data Collection Methods}

Structured questionnaires were used to collect quantitative data from 50 medical and nursing staff. The questionnaires were submitted to 60 medical and nursing staff to collect quantitative data. A semi-structured questionnaire was used to conduct a key informant in-depth interview with an HRM officer. A question guide was used for 3 focus group discussions. Separate focus group discussions were done with 8 nurses, 6 clinical officers and 8 doctors.

\subsection{Methods of Data Analysis}

Quantitative data was entered directly into the Statistical Package for Social Scientists (SPSS) 16 for Windows software. Data analysis was done using the SPSS software and where necessary was exported to Microsoft Excel for further processing. Qualitative data was recorded in hard copy. Transcripts of qualitative data were analysed throughout data collection to determine when data saturation was reached. Transcripts were reviewed to identify relevant and prominent themes, narratives and memorable quotes captured from focus group discussions and key informant interview. Themes coming out of transcripts were coded for easy interpretation. By the time the third group discussion was done no more new information was coming from the discussions.

\subsection{Ethics Considerations}

A written informed consent was provided to respondents. They were asked to choose whether to participate in the study or not based on the content of the informed consent note. This study strictly observed privacy and confidentiality on information provided.

\section{Findings}

\subsection{Findings on Impact of Work Environment on Staff Morale}

Findings from focus group discussions revealed that doctors and nurses were frustrated with poor compensation, heavy workloads, inadequate resources and inadequate housing allowances. Discussions with clinical officers 
highlighted lack of resources, equipment and in-service training as key demoralizing factors. The group discussion with nurses further indicated that nurses were frustrated with lack of training opportunities, inequitable career development opportunities, poor supportive supervision and lack of management appreciation towards their contributions. Nurses indicated that they had no one to turn to if they had problems and needed support. Lack of resources was mentioned in all the three group discussions as a challenge. Discussions with doctors and nurses highlighted poor compensation, work load and poor housing as challenges. On the other hand nurses and clinical officers complained of lack of training opportunities. An in-depth interview with the HRM manager corroborated these findings. The HR manager revealed that medical and nursing staff had ever complained about staff shortages, lack of resources and poor housing.

Data collected through structured questionnaires revealed that medical and nursing members of staff perceived staffing levels to be on the lower side. Seventy-six percent (76\%) of respondents strongly disagreed that there was enough staff at KCH. Not surprising, forty percent $(40.4 \%)$ of respondents $(n=47)$, reported feeling fatigue a few times per week while, $12.8 \%$ reported burn out every day in the past 1 year. Large percentages of medical and nursing staff indicated that they were not at all satisfied with resource availability (83.7\%), salary (81.6\%), educational (66.0\%) and training opportunities (66.0\%). However, respondents were somewhat satisfied with working hours; for instance $83.6 \%$ of respondents were somewhat satisfied or satisfied with working hours. Fifty eight percent (58\%) of respondents strongly disagreed that management at the hospital listens and responds to staff concerns. The Fisher's exact test showed that job satisfaction was significantly associated with management responsiveness (p-value of 0.009). Fisher's exact test also showed a significant association between job satisfaction and salary levels (p-value 0.012 ).

\subsection{Findings on Impact of HR Policies on Staff Morale}

The second objective was to determine the effect of MoH HR policies on staff morale. The study revealed that the hospital had no clear performance management policy. The hospital did not have its own training and staff promotion policy. The MoH Head Quarters was in control of recruitment, staff promotion, long term training and compensation. Lack of autonomy on staff promotion, long term training and staff benefits was frustrating to both KCH management and staff members. Members of staff were demoralised with lack of education opportunities, poor staff benefits and inadequate performance management which occurred as a direct result of a weak HR policy environment at $\mathrm{KCH}$.

Focus group discussions showed that members of staff were not satisfied with training, promotion and performance management policies. Training and promotions were done haphazardly. Due to unavailability of a performance management system, doctors and nurses indicated that they were not recognized for a job well done and there were no sanctions for non-performers. Questionnaire data showed that almost half of the respondents (52.2\%), $\mathrm{n}=46$, indicated that they are frustrated with the policy used to decide who gets promoted at KCH. Similarly, forty-six percent of respondents $(46.2 \%), \mathrm{n}=39$, reported that they were not satisfied with the performance evaluation at the Hospital. Group discussions with nurses showed that nurses were not satisfied with settlements and allowance policies.

\subsection{Findings on HR Management Strategies and Their Impact on Staff Morale}

The third objective was to assess HRM initiatives currently in practice at $\mathrm{KCH}$ and evaluate their impact on staff morale. Respondents were not impressed with management strategies aimed at motivating staff. Initiatives such as housing allowance, professional allowances and a 52\% salary top up introduced in the year 2005 were no longer effective. These had been drastically watered down by very high inflation rates experienced in Malawi during the period 2011-2013. In addition, members of staff regarded locum allowances (overtime allowance) as a nonimpactful initiative because it did not meet their needs.

Forty-five percent (45\%) of respondents were moderately satisfied with their jobs while $30.6 \%$ were very dissatisfied with their jobs. Low morale amongst staff was evidenced by intention to leave KCH; $57 \%$ wished they left the Hospital within a period of 12 months. Information from structured questionnaires revealed a number of factors that could make respondents think of leaving their jobs. Key ones mentioned were openings outside the country (44.7\%); feeling unsupported by management (42.64\%) and concern with quality of care (40.4\%). The $\mathrm{HR}$ manager linked attrition at $\mathrm{KCH}$ to failure for the hospital to meet staff needs mainly resources for work, fair compensation, and career development opportunities. He recommended that managerial activities should be de- 
volved to departments to provide more support to staff members.

\subsection{Findings on Factors That Enhance Staff Morale}

The fourth objective of this study was to identify key factors that would enhance the morale of medical and nursing staff at $\mathrm{KCH}$. According to group discussions, common factors with potential to boost staff morale were improved availability of resources for helping patients, training opportunities, better salaries, reduced workloads, access to career development opportunities and improved staff welfare. Additional factors with potential to boost the morale of doctors were adequate housing allowances and loans for purchasing motor vehicle or houses. Morale boosting factors specific for nurses were improved supportive supervision and management appreciation towards their contributions. Clinical officers indicated that their morale could be boosted with provision of equipment and in-service training. Other factors that were deemed motivational were implementation of a clear performance management system, recognition awards and adequate prevention of occupational exposure.

Asked about which characteristics of their present job would encourage them to stay in their job, $38.3 \%$ of respondents indicated that they would stay because of educational opportunities; and 34\% cited good relations with colleagues. Based on recurrent themes from the three key data collection techniques employed in this study, factors that could enhance staff morale at $\mathrm{KCH}$ included adequate support from supervisors, manageable work load, prevention of occupational exposure, provision of educational opportunities, good relations with other staff members and ability to provide high quality of care to patients.

\section{Discussion}

Respondents complained of several de-motivating factors in the work environment including heavy workloads, poor compensation, inadequate resources, lack of training opportunities, lack of career development opportunities, poor supervision and lack of management appreciation. These findings are in agreement with a USA MoH Report [7] and a study by Paradith [9] that cited uncontrolled workloads, inadequate resources, poor supervision and inadequate training opportunities as key factors that could negatively impact on staff morale. It is not surprising therefore, that respondents were frustrated with the work environment at $\mathrm{KCH}$, as evidenced by a substantial percentages (57.1\%) of staff who were intending to leave and a considerable percentage (47\%) of those who were not fully satisfied with their jobs. Findings on the work environment at KCH are also consistent with those from a study conducted by McAuliffe et al. 2008 in district hospitals in Malawi.

$\mathrm{KCH}$ had no clear HR strategy as evidenced by lack of training, performance management and staff development strategies. Respondents registered dissatisfaction with key HRM policies including training, promotion and performance management. This finding was in agreement with that of McAuliffe et al., [6] who noted that MoH policies on training and development were unclear at district level. A study by the MoH-SWAp [11] also showed that Malawi had a weak career development policy for health workers. This study showed that nursing staff had inadequate management support. Palmer [5] reported that management practices were as important an incentive as pay. Poor HR management therefore was one of the main critical factors that were demoralizing members of staff at $\mathrm{KCH}$.

In their study, Carlson et al. [16] and DFID [17] reported that the Malawi MoH put in place a range of HR initiatives to motivate staff. They cited locum allowances in all hospitals and 52\% salary top up among others. However, findings from this study demonstrate that these initiatives had no significant impact by August 2013. The 52\% salary top up may have been subdued by high inflation rates that hit Malawi in 2012. Inflation rates sky rocketed within the year 2012 from 10.3\% to 39.0\% [29]. Apparently KCH had no strategies in place to motivate staff.

Respondents indicated that improving salaries levels, availability of resources, career pathways, housing and training could boost their working morale. These findings are also in agreement with Armstrong's [8] who argued that employees seek either intrinsic or extrinsic benefits from an organization. Members of staff were in need of responsive management, resources and career development primarily to meet their intrinsic needs. On the other hand, they needed good salaries and housing to meet their extrinsic needs. The Maslow's hierarchy of needs could be helpful in understanding what motivates employees, Armstrong [8]. It was clear from this study that doctors whose professional status was higher than the other cadres were eyeing more luxurious needs such as car loans, medical insurance and proper housing to boost their self-esteem among others things. All members of staff wished they could get better salaries and benefits in order to meet their various needs. 


\section{Conclusion}

Key factors that could enhance staff morale were identified. These are: improved availability of resources for helping patients, training opportunities, better salaries, reduced workloads, access to career development opportunities, improved staff welfare and performance management. Some needs were specific to doctors, for example motor vehicle loans. Centralization of HRM functions negatively affected implementation of key HRM strategies such as career development, recruitment and training. However, $\mathrm{KCH}$ has the mandate to manage other impactful HR activities including performance management, praise and recognition and workloads. Other factors were consequences of the macro-economic environment, most notably poor compensation and inadequate resources for work.

\section{Recommendations}

1) $\mathrm{MOH}$ and stakeholders should explore ways to support devolution of central hospitals. This will enable hospitals to generate income for improving service delivery and easing some HR related challenges.

2) Management should devolve some HR activities to line managers, prior to training them in HRM and general management.

3) Department heads should be holding regular meetings to listen to challenges and staff needs.

4) $\mathrm{MoH}$ should support tertiary hospitals to have constant supplies of drugs, medical commodities and hospital equipment. The ministry needs to advocate for more funds from government and development partners to support procurement of hospital resources as a matter of urgency. Shortage of resources was identified as a very key demotivating factor to all cadres of health workers included in this study.

5) $\mathrm{MoH}$ should support tertiary hospitals to provide appropriate housing for doctors and other critical staff. The ministry needs to advocate for more funds from government and development partners to support construction of institutional houses or provision of housing allowances for senior medical and nursing cadres.

6) $\mathrm{KCH}$ management should identify seed money for running a revolving fund that can be used to provide loans to medical doctors and other interested members of staff by the end of 2014.

7) $\mathrm{KCH}$ should scale up paying services and put in place a market oriented management system so that $\mathrm{KCH}$ paying services can compete effectively on the market.

\section{Acknowledgements}

Dr. Chiwaula thanks for facilitating approval to conduct this study at Kamuzu Central Hospital. Many thanks Dr. Kajombo, Mr. Malanda and Mr. Bingo of KCH for assisting in data collection.

\section{References}

[1] Ministry of Economic Planning and Development (2011) Malawi Growth and Development Strategy II: 2011-2016, Lilongwe.

[2] Ministry of Health (2011) Health Sector Strategic Plan 2011-2016, Lilongwe.

[3] Huddart, J. and Picazo, O.F. (2003) The Health Sector Human Resource Crisis in Africa. Academy for Educational Development. An Issue Paper, Washington DC.

[4] Muula, A. and Maseko, F. (2005) Survival and Retention Strategies for Malawian Health Professionals. Regional Network for Equity in Health in Southern Africa. EQUINET Discussion Paper No. 32.

[5] Palmer, D. (2006) Tackling Malawi’s Human Resources Crisis. Reproductive Health Matters, 14, 27-39. http://dx.doi.org/10.1016/S0968-8080(06)27244-6

[6] McAuliffe, M.O., Bowie, C., Maseko, F., MacLachlan, M. and Normand, C. (2008) Maximising Human Resource Capacity in Rural District Health Systems in Malawi, Lilongwe.

[7] United States of America's Ministry of Health (2006) What Makes a Healthy Work Environment? http://www.health.gov.bc.ca/environments/workplace/healthyworkplace.html

[8] Armstrong, M. (2006) A Hand Book of Human Resource Management Practice. Kogan Page, London.

[9] Paradath, A., Chamberlain, C., McCoy, D., Ntuli, A., Rowson, M. and Loewenson R. (2003) Health Personnel in Southern Africa: Confronting Maldistribution and Brain Drain. EQUINET Discussion Paper No. 3.

[10] Ministry of Health (2008) Malawi Health SWAp Mid-Term Review: NORAD Collected Reviews, Lilongwe. 
[11] GTZ/Malawi Health SWAp (2007) Human Resources/Capacity Development within the Health Sector. Needs Assessment Study, Lilongwe.

[12] Noe, R., Hollenbeck, J., Gerhart, B. and Wright, P. (2010) Human Resource Management: Gaining a Competitive Advantage. McGraw Hill, New York.

[13] Pearce, J.A. and Robinson, R.B. (2011) Strategic Management: Formulation, Implementation and Control. McGraw Hill, New York.

[14] Mathauer, I. and Imhoff, I. (2006) Health Worker Motivation in Africa: The Role of Non-Financial Incentives and Human Resource Management Tools. Human Resources for Health, 4, 24. http://dx.doi.org/10.1186/1478-4491-4-24

[15] Dambisya, Y. (2007) A Review of Non-Financial Incentives for Health Worker Retention in East and Southern Africa. Proceedings of Equinet Discussions, University of Limpopo, South Africa, Paper No. 44.

[16] Carlson, C., Boivin, M., Chirwa, A., Chirwa, S., Chitalu, F., Hoare, G., Huelsmann, M., Ilunga, W., Maleta, K., Marsden, A., Martineau, T., Minett, C., Mlambala, A., Massow, F., Njie, N. and Olsen, I. (2008) Malawi Health SWAp Mid-Term Review. Norad Collected Reviews.

[17] Department for International Development (2010) Evaluation of Malawi’s Emergency Human Resources Programme.

[18] Mangham, L. (2007) Addressing the Human Resource Crisis in Malawi’s Health Sector: Employment Preferences of Public Sector Registered Nurses. ESAU Economic and Statistical Analysis Unit, London, March 2007, Working Paper 18.

[19] Herzberg, F. (1964) The Motivation-Hygiene Concept and Problems of Manpower. Personnel Administration, 27, 3-7.

[20] Grobler, P., Warnich, S., Carrell, M., Elbert, N. and Hatfield, R. (2006) Human Resource Management in South Africa. Thomson, Pat Bond, London.

[21] Deloitte and Touch (2010) Compensation Strategies: How to Reward and Retain Employees on a Tight Comp Budget. http://www.deloitte.com/assets/dcom-global/local\%20assets/documents/human\%20capital/us_talent2020_september20 12_09142012.pdf

[22] Health Systems Strengthening for Equity (2008) Factors Affecting Job Satisfaction and Retention in Malawi, Mozambique and Tanzania: The Importance of Supervision.

[23] McCord, C., Mbaruku, G., Pereira, C., Nzabuhakwa, C. and Bergstrom, S. (2009) The Quality of Emergency Obstetrical Surgery by Assistant Medical Officers in Tanzanian District Hospitals. Health Affairs, 28, 876-885.

[24] Pereira, C., Cumbi, A., Malalane, R., Vaz, F., McCord, C., Bacci, A. and Bergström, S. (2007) Meeting the Need for Emergency Obstetric Care in Mozambique: Work Performance and Histories of Medical Doctors and Assistant Medical Officers Trained for Surgery. BJOG: An International Journal of Obstetrics and Gynaecology, 114, 1530-1533. http://dx.doi.org/10.1111/j.1471-0528.2007.01489.x

[25] Ntuli, A. (2006) Regional Evidence and Perspectives on Migration of Health Workers. Proceedings of a Regional Planning Meeting: Retention and Migration of Health Personnel in Southern Africa, Lusaka.

[26] Awases, M., Gbary, A., Nyoni, J. and Chatora, R. (2004) Migration of Health Professionals in Six Countries: A Synthesis Report. WHO-AFRO DHS, Brazaville.

[27] Saunders, M., Lewis, P. and Thornhill, A. (2012) Research Methods for Business Students. Pearson Education Ltd., Harlow.

[28] Morris, C. (2012) Quantitative Approaches in Business Studies. 8th Edition, Pearson Education Ltd., Harlow.

[29] Alliance Capital Ltd. (2013) Business-Daily Market Data. The Daily Times, 13 August 2013, 10. 
Scientific Research Publishing (SCIRP) is one of the largest Open Access journal publishers. It is currently publishing more than 200 open access, online, peer-reviewed journals covering a wide range of academic disciplines. SCIRP serves the worldwide academic communities and contributes to the progress and application of science with its publication.

Other selected journals from SCIRP are listed as below. Submit your manuscript to us via either submit@scirp.org or Online Submission Portal.
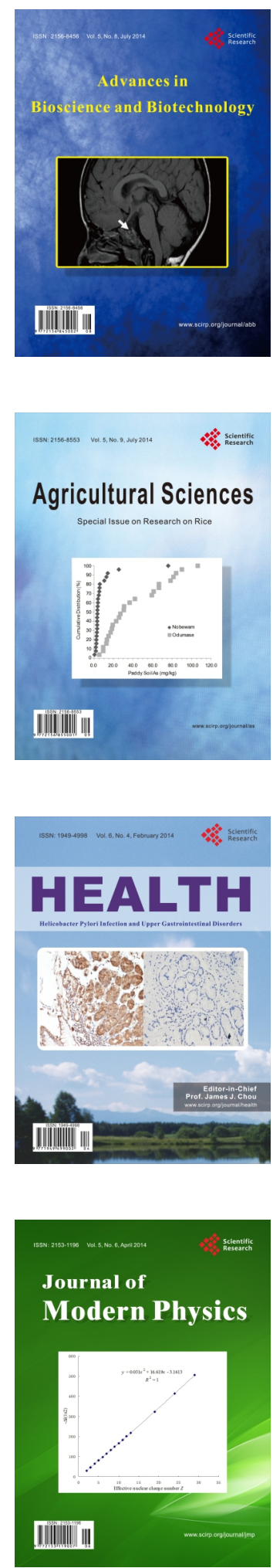
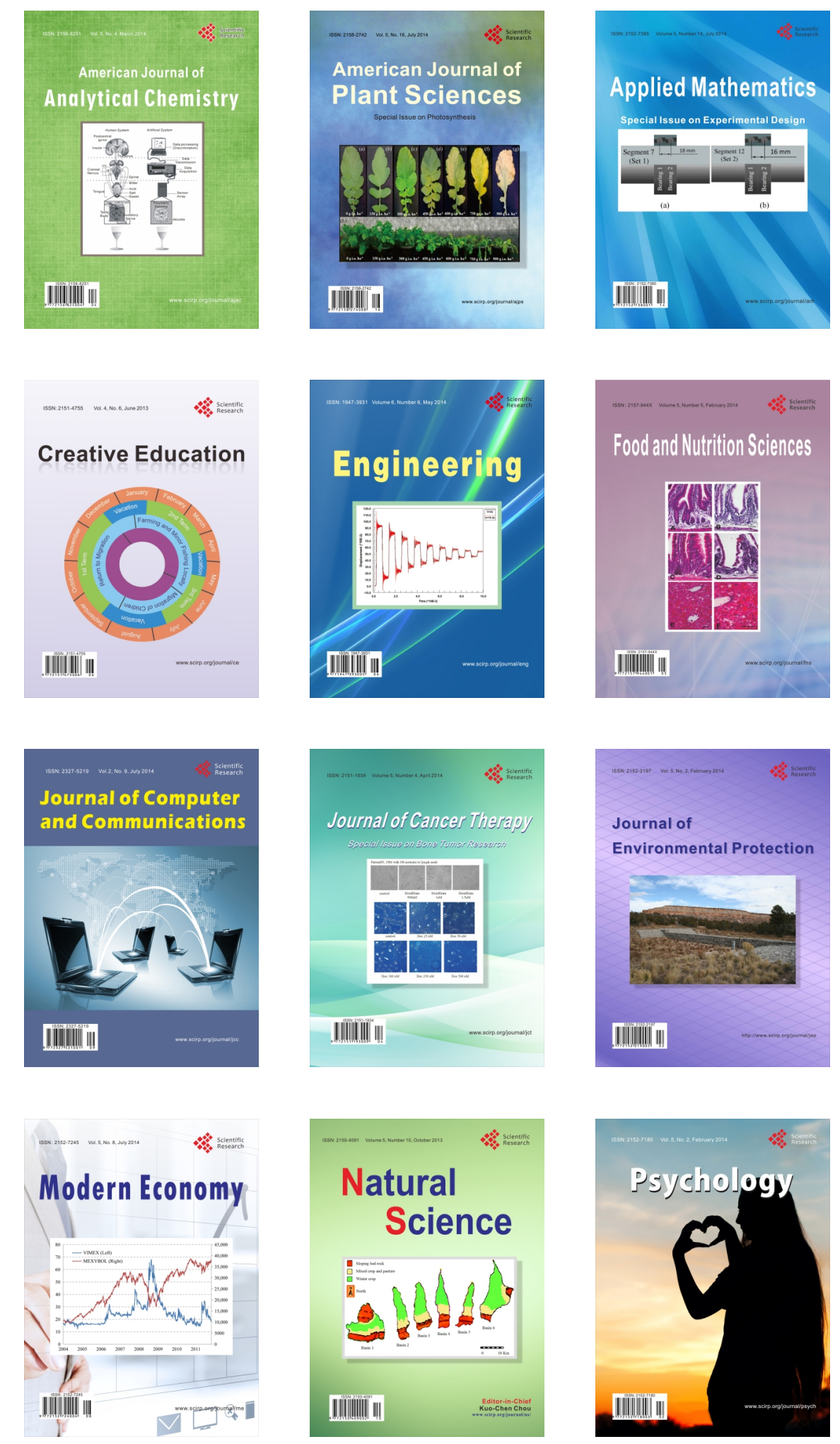